\section{Assessment of Tooth Structure using an Alternative Electrical Bioimpedance Spectroscopy Method}

Andréa Pereira Morais ${ }^{1,3}$, Alexandre Visintainer Pino ${ }^{1}$, Marcio Nogueira Souza ${ }^{1,2}$
'Biomedical Engineering Program, COPPE, UFRJ - Federal University of Rio de Janeiro, Rio de Janeiro, RJ, Brazil

${ }^{2}$ Electronics Department at Polytechnic School, UFRJ - Federal University of Rio de Janeiro, Rio de Janeiro, RJ, Brazil ${ }^{3}$ UNIVERSO - Salgado de Oliveira University, São Gonçalo, RJ, Brazil

Correspondence: Marcio Nogueira de Souza, Avenida Horácio Macedo 2030, Centro de Tecnologia, Bloco H, s/327, llha do Fundão, CEP 21949-900, Rio de Janeiro - RJ, Brasil. Tel: + 55-213938-8582. e-mail: souza@peb.ufrj.br

Key Words: bioimpedance, tooth structure, dental health.

\section{Introduction}

Bioimpedance spectroscopy (BIS) can be defined as the evaluation of the frequency-dependent electrical opposition (both real and imaginary components) to the flow of an alternating current through a biological specimen as a result of an applied electric voltage. Such technique has been used to measure different aspects of physiological or pathological events, and has important advantages, such as be noninvasive, simple, fast, and painless; besides presenting reasonable costs.

Due to above-mentioned characteristics, measurement techniques based on bioimpedance have been used in dentistry, for example, in estimating the length of root canals and to evaluate the physical properties of the teeth hard-tissues, specially enamel and dentin (1-5). BIS has also been proposed as a feasible technique for caries detection, particularly in difficult diagnostic cases (6-9). As the caries process advances and the tooth structure demineralizes, there is an increase of the porosity of the hard tissues of the tooth. These structures progressively break down to form a cavity and since such porosity/cavity is filled with an artificial electrolyte fluid (contact media) or saliva from the oral environment it is expected the impedance of tooth can be used to assess these structural changes $(10,11)$.

However, despite the significant number of studies using bioimpedance to investigate the dental structure, many of them use only the real component of bioimpedance, i.e., the resistance, disregarding the information provided by the imaginary one, i.e., the reactance. Moreover, most of the papers in the literature that investigate both parts of bioimpedance, obtain their data using single frequency or multifrequency methods based on sinusoidal sweep $(1,3,6,10-12)$.

This paper investigates the feasibility of an alternative BIS method based on the current response to a voltage step excitation to assess tooth structure. The main advantage of such method is that it uses a single step waveform to characterize the bioimpedance frequency dependency, since theoretically only one excitation signal scans all frequency components.

\section{Material and Methods Experimental Protocol and Data Acquisition}

The feasibility of the alternative method was investigated using 22 teeth, 9 intact third molars (TM) and 13 intact premolars (PM) in an in vitro protocol. All teeth had been extracted for orthodontic reasons and were autoclaved in distilled water for $40 \mathrm{~min}$ and stored in saline solution under constant refrigeration (13). The study was performed after approval by the Ethics Committee of 
the Institute of Studies in Collective Health of the Federal University of Rio de Janeiro, Brazil (Process 04/2009, CAAE 0005.0.239.000-09).

An in vitro experimental setup (Fig. 1 A left side) was used to evaluate the application of the alternative BIS method in assessing changes in the tooth structure. The setup consisted of a bowl of saline solution with a mechanical support that held the tooth in an upright position allowing the root of the tooth to be in contact with the saline solution. Two electrodes were used in the experiment. One of those electrodes was a stainless steel rod in contact with the saline solution and the other was a stainless steel explorer electrode that was used to investigate the surfaces of the tooth. To promote low contact impedance between the tooth and the explorer electrode a saline gel was used in the tip of such electrode.

The alternative BIS method is the one based on the current response of a voltage step excitation (14). Despite being a method in time domain it is equivalent to a spectroscopy method in the frequency domain because theoretically one step excitation signal scans all frequency components. Briefly, the hardware of the system applies a step voltage $(900 \mathrm{mV})$ to the tooth and measures the current response by using a current-to-voltage preamplifier and a 12 bits- $500 \mathrm{kHz}$ acquisition card (PCM-CIA model DAOCard AI-16E-4; National Instruments, Austin, TX, USA). The hardware of the prototype is controlled by a program developed in LabView (National Instruments) running on a mobile hardware platform.

In the BIS approach, it is necessary to consider an electrical model to the biological sample under investigation in order to achieve a theoretical expectation of the current response, which is used to estimate the electrical parameters associated to the bioimpedance. Thus, to represent the experimental setup depicted in Figure 1 A we proposed the electrical model illustrated in Figure
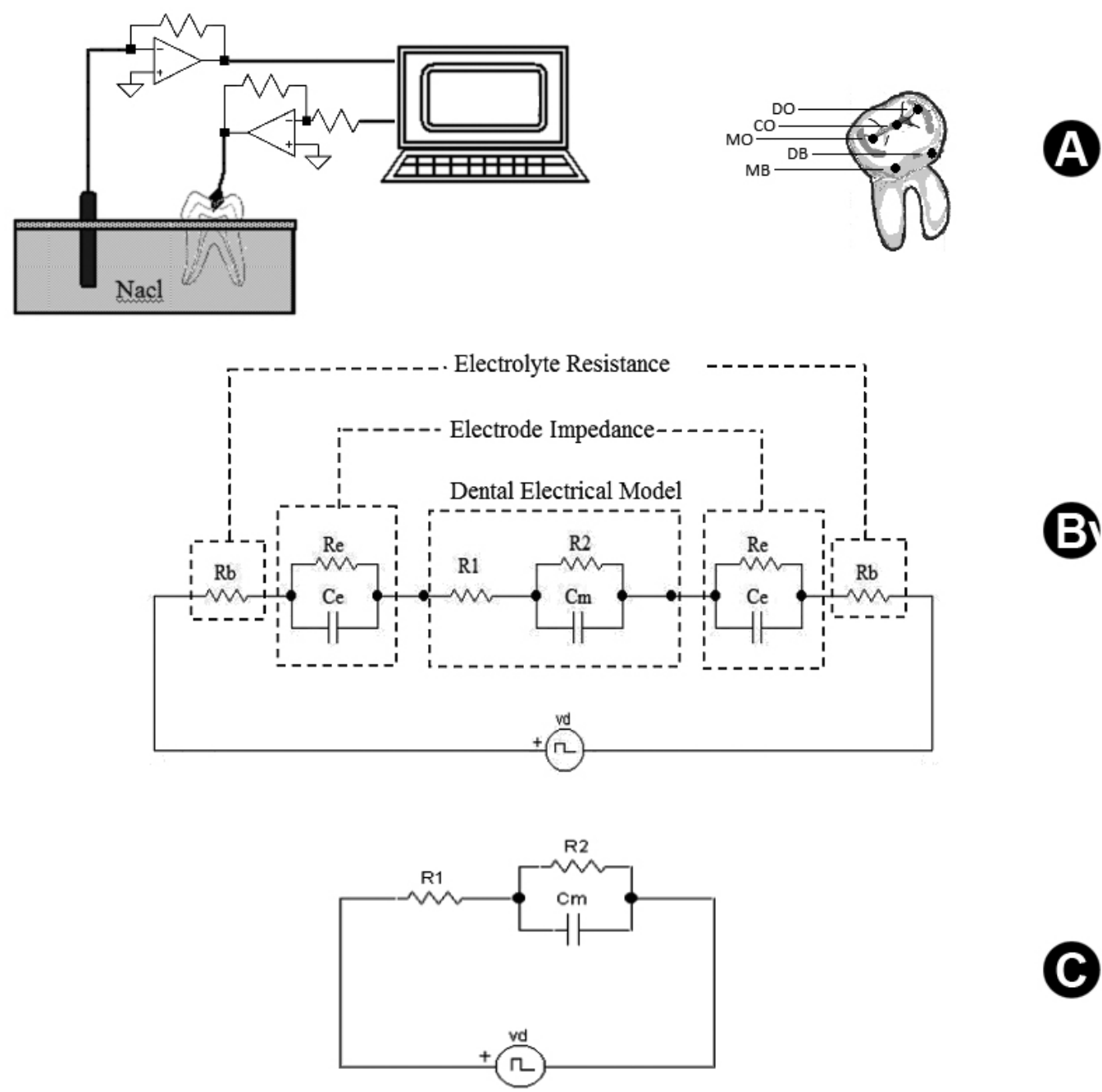

Figure 1. A: Illustration of the experimental setup (left side) and five out of the seven sites investigated (right side) (CO - centro-occlusal, MO - mesioocclusal, DO - disto-occlusal, MB - mesio-buccal and DB - disto-buccal). B: Electrical model for the experimental setup. C: Simplified model used to estimate the current response to the step voltage excitation. See the text for more details. 
$1 \mathrm{~B}$, where $R_{1}$ and $R_{2}$ are resistive parameters associated with the enamel layer and to the dentine-pulp structures, respectively. The parameter $\mathrm{Cm}$ represents the capacitive aspects of the dentine-pulp structures.

A set of preliminary experiments was carried out to establish the influence of some aspects, such as, the electrode impedance, the electrolyte gel used in the explorer electrode, and the equivalent resistance of the saline solution. As observed by Huysmans et al. $(12,15)$, all these factors were found to be negligible compared with the impedance of the tooth. Thus, according to the hypothesis that the dental impedance is much higher than either the electrolyte equivalent resistance or the impedance due to the electrode/electrolyte interface, the electrical model representing the experimental setup (Fig. 1B) can be simplified to the model depicted in Figure 1C. Based on the simplified model, the current response to a voltage step excitation is described by Equation 1.

$$
i(t)=I p\left(1+\frac{R_{2}}{R_{1}} e^{-\frac{t}{r}}\right)
$$

where

\section{[Equation 1]}

$$
I p=\frac{v d}{\left(R_{1}+R_{2}\right)}, v d \text { is the magnitude of the voltage }
$$
step and

$$
\boldsymbol{x}=\frac{\left(R_{1} R_{2}\right)}{\left(R_{1}+R_{2}\right)} \mathrm{Cm}
$$

From the theoretical estimate of the current response (Equation 1) and its experimental counterpart, the parameters of the simplified electric model were estimated using a multiparametric optimization method (steepest-descent gradient method). Figure 2 depicts an example of experimental data superimposed by the prediction of Equation 1 and calculated using the "bestfit" parameters.

\section{Sites of Data Acquisition}

Using the stainless steel explorer electrode, bioimpedance data were acquired in 7 sites of intact healthy dental surfaces (Fig. 1A right side). Three out of the 7 sites were on fissure surfaces ( $\mathrm{CO}$ - centro-occlusal, MO - mesio-occlusal, DO - disto-occlusal) and 4 on smooth surfaces, of which 2 sites were on lingual surfaces (DL - disto-lingual, ML - mesio-lingual) and 2 on buccal surfaces (DB - disto-buccal, MB - mesio-buccal). During the experiments, the temperature and humidity of the room were set and monitored at $23{ }^{\circ} \mathrm{C} \pm 1{ }^{\circ} \mathrm{C}$ and $80 \%$ $\pm 10 \%$, respectively.

\section{Artificial Changes in the Tooth Structure and Data Analysis}

To investigate the sensitivity of the alternative BIS method in evaluating changes in the tooth structure, successive layers of enamel were removed by drilling the smooth areas of nine healthy third molars and six healthy premolars with a $1.0 \mathrm{~mm}$ cylindrical dental drill. For each experimental condition BIS data were collected and values of $R_{1} R_{2}$ and $C m$ estimated by fitting the experimental data as mentioned before. Such parameters for intact teeth (IT group) were compared with those for the teeth that were drilled to 2 depths, $0.5 \mathrm{~mm}$ for groups 1TM (third molars) and 1PM (premolars); and $1.0 \mathrm{~mm}$ for groups 2TM (third molars) and 2PM (premolars).

Experimental data were analyzed using SPSS 17.0 (SPSS Inc., Chicago, IL, USA). Shapiro Wilks was used to determine data distribution and non-parametric tests Mann-Whitney, Kruscal Wallis and Wilcoxon were applied where appropriated. A significance level of $5 \%$ was considered in all statistic tests. Data are presented as mean

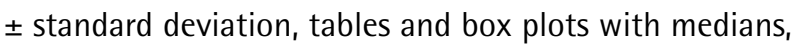
quartiles and outliers.

\section{Results}

Less than $1 \%$ of the all measurements performed on the teeth presented a very low signal-to-noise ratio and were removed from the study. Mean values and standard deviations for the parameters $R_{1}, R_{2}$ and $\mathrm{Cm}$ for the 22 intact studied teeth can be seen in Table 1 (TM teeth) and Table 2 (PM teeth).

The estimate parameters for the TM and PM teeth

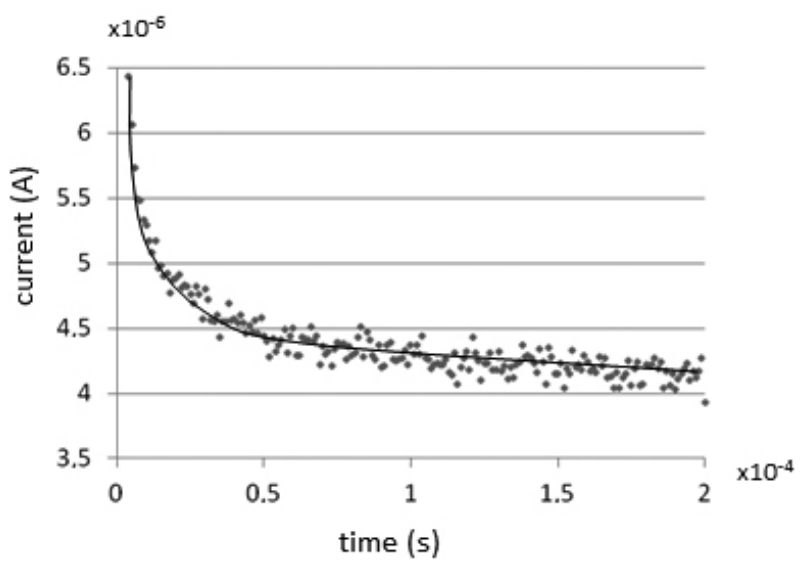

Figure 2. Example of an experimental current response to a voltage step collected in a vestibular face of third molar tooth, superimposed by the prediction of eq. (1) calculated using the "best-fit" parameters. See the text for more details. 
presented no statistically significant differences considering the studied sites on the same surface. Thus, these parameters were merged in four groups: TM fissure, TM smooth, PM fissure and PM smooth. In this case there were statistical difference $(p<0.05)$ between smooth and fissure faces

Table 1. Mean and standard deviation of bioimpedance parameters of intact third molar teeth (TM), considering the studied faces

\begin{tabular}{|c|c|c|c|c|}
\hline \multirow{2}{*}{ Face } & \multirow{2}{*}{$\begin{array}{l}\text { Measured } \\
\text { site }\end{array}$} & \multicolumn{3}{|c|}{ Bioimpedance parameters } \\
\hline & & $R_{1}(\mathrm{k} \Omega)$ & $R_{2}(\mathrm{k} \Omega)$ & $\mathrm{Cm}(\mathrm{pF})$ \\
\hline \multirow{3}{*}{$\begin{array}{l}\text { Fissure } \\
\text { surfaces }\end{array}$} & $\operatorname{CO}(n=13)$ & $231 \pm 147$ & $56 \pm 10$ & $4.1 \pm 0.9$ \\
\hline & MO $(n=12)$ & $393 \pm 250$ & $64 \pm 13$ & $3.5 \pm 1.6$ \\
\hline & DO $(n=12)$ & $494 \pm 293$ & $66 \pm 10$ & $3.3 \pm 0.7$ \\
\hline \multirow{4}{*}{$\begin{array}{l}\text { Smooth } \\
\text { surfaces }\end{array}$} & DB $(n=13)$ & $1096 \pm 805$ & $67 \pm 10$ & $3.1 \pm 0.5$ \\
\hline & $\mathrm{MB}(\mathrm{n}=13)$ & $940 \pm 778$ & $64 \pm 14$ & $3.5 \pm 1.6$ \\
\hline & $\operatorname{DL}(n=13)$ & $876 \pm 455$ & $68 \pm 13$ & $3.1 \pm 0.7$ \\
\hline & ML (n=13) & $1315 \pm 909$ & $69 \pm 10$ & $3.0 \pm 0.5$ \\
\hline
\end{tabular}

CO: centro-occlusal, MO: mesio-occlusal, DO: disto-occlusal, DB: distobuccal, MB: mesiobuccal, DL: distolingual, ML: mesiolingual.

Table 2. Mean and standard deviation of bioimpedance parameters of intact premolar teeth (PM), considering the studied faces

\begin{tabular}{lcccc}
\hline \multirow{2}{*}{ Face } & Measured & \multicolumn{3}{c}{ Bioimpedance parameters } \\
\cline { 3 - 5 } & site & $R_{1}(\mathrm{k} \Omega)$ & $R_{2}(\mathrm{k} \Omega)$ & $\mathrm{Cm}(\mathrm{pF})$ \\
\hline \multirow{3}{*}{$\begin{array}{c}\text { Fissure } \\
\text { surface }\end{array}$} & MO $(\mathrm{n}=13)$ & $552 \pm 266$ & $72 \pm 11$ & $3.1 \pm 0.6$ \\
& DO $(\mathrm{n}=12)$ & $515 \pm 230$ & $69 \pm 10$ & $3.2 \pm 0.6$ \\
& DB $(\mathrm{n}=13)$ & $1547 \pm 627$ & $71 \pm 9$ & $2.8 \pm 0.1$ \\
Smooth & MB $(\mathrm{n}=13)$ & $1399 \pm 651$ & $71 \pm 7$ & $2.9 \pm 0.1$ \\
surfaces & DL $(\mathrm{n}=13)$ & $1587 \pm 1047$ & $74 \pm 9$ & $2.8 \pm 0.1$ \\
& ML $(\mathrm{n}=13)$ & $1228 \pm 1144$ & $72 \pm 9$ & $2.9 \pm 0.4$ \\
\hline
\end{tabular}

CO: centro-occlusal, MO: mesio-occlusal, DO: disto-occlusal, DB: disto-buccal, MB: mesiobuccal, DL: disto-lingual, ML: mesio-lingual.

Table 3. Means and standard deviations of bioimpedance parameters of intact third molars (TM, $n=60$ faces) and premolars (PM, $n=89$ faces)

\begin{tabular}{lcccc}
\hline \multirow{2}{*}{ Teeth } & Face & \multicolumn{3}{c}{ Bioimpedance parameters } \\
\cline { 3 - 5 } & & $R_{1}(\mathrm{k} \Omega)$ & $R_{2}(\mathrm{k} \Omega)$ & $\mathrm{Cm}(\mathrm{pF})$ \\
\hline \multirow{2}{*}{$\mathrm{TM}$} & Fissure & $337 \pm 264$ & $63 \pm 16$ & $3.6 \pm 0.8$ \\
& Smooth & $957 \pm 766$ & $67 \pm 12$ & $3.2 \pm 0.9$ \\
& Fissure & $745 \pm 1042$ & $71 \pm 9$ & $3.0 \pm 0.6$ \\
PM & Smooth & $1456 \pm 1014$ & $71 \pm 9$ & $2.9 \pm 0.2$ \\
\hline
\end{tabular}

(Table 3) for the $R_{1}$ and $\mathrm{Cm}$ parameters.

After observing the data of intact teeth, estimate values of $R_{1}, R_{2}$ and $\mathrm{Cm}$ were organized in box plot for the intact teeth and for the respective drilling depths of $0.5 \mathrm{~mm}$ and

A

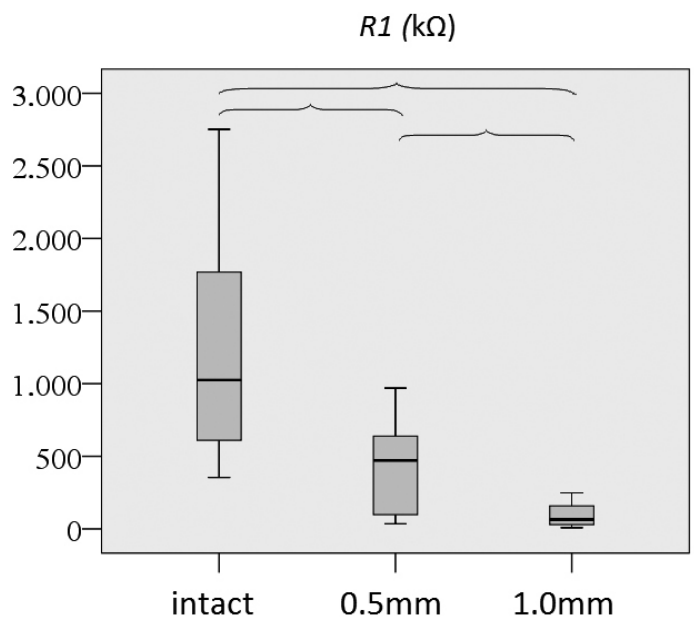

B

$R 2(\mathrm{k} \Omega)$

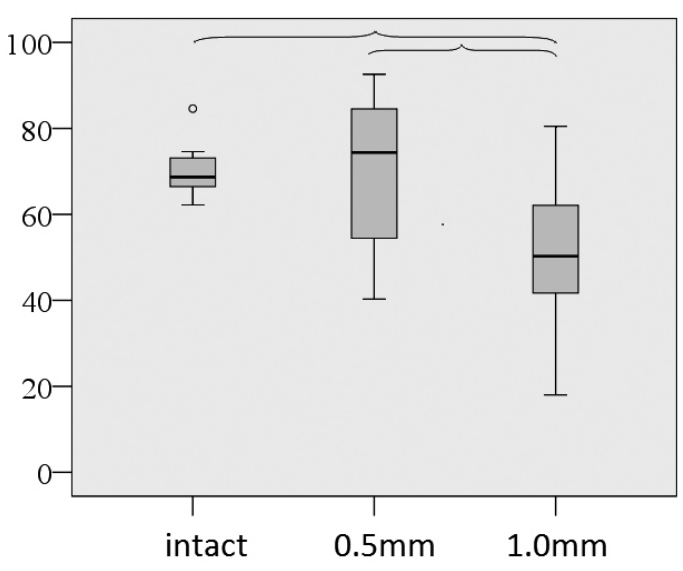

C

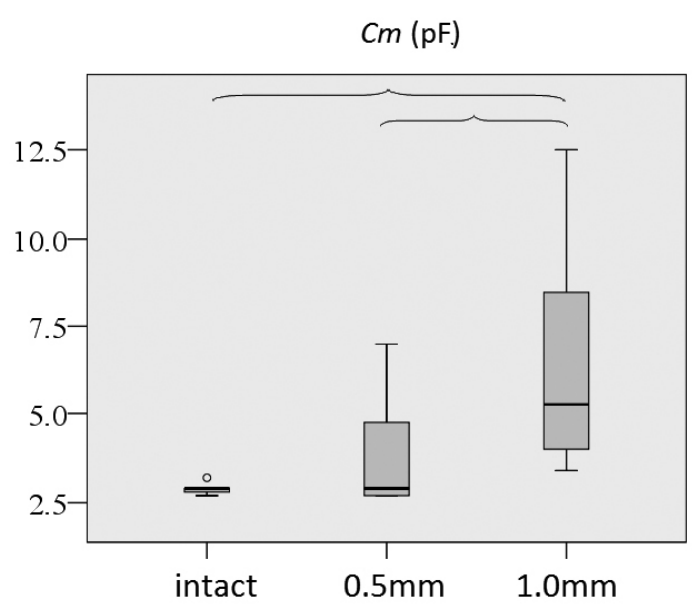

Figure 3. Box plots of the bioimpedance parameters $R_{1}(\mathrm{~A}), R_{2}(\mathrm{~B})$, and $\mathrm{Cm}$ (C) for intact teeth and for the respective drilling depths of $0.5 \mathrm{~mm}$ and $1.0 \mathrm{~mm}$ observed in premolars and in third molars $(n=15)$. The groups linked by brackets indicate statistical significant difference $(p \leq 0.05)$. 
$1.0 \mathrm{~mm}$ (Figs. 3A, 3B and 3C, respectively). Those figures show a remarkable decrease in $R_{1}$ and $R_{2}$ and an increase of $\mathrm{Cm}$ with the removal of successive layers of enamel.

In order to normalize raw bioimpedance parameters, Huysmans et al. (15) proposes the logarithmic inverse of the sum of the resistances as the best parameter to analyze teeth structure. This index (HI) was applied to our data and the results can be seeing in Figure 4 .

The $\mathrm{HI}$ seemed to be a good tool to discriminate the 3 stages of drilling process with a $p$ value of 0.002 (Wilcoxon test) between groups. This index uses only the real component of bioimpedance, the resistance; disregarding the information provided by the imaginary one, i.e., the reactance.

We propose an alternative index that uses both parts (resistive and reactive) of bioimpedance, the Dental Health Index (DHI). To formulate this index were observed parameters and their variations. Values of $R_{1}$ seem to be the most discriminative in the proposed electric dental model. Additionally, $R_{2}$ values present the same behavior of $R_{1}$ values but with smaller variation and could be used to normalize the resistive data. Finally, $\mathrm{Cm}$ values had a marked increase despite its wide variation. These observations led to the proposition of the index DHI described by equation (2).

$$
D H I=\frac{\log \left(R_{1}\right)}{\log \left(R_{2}\right)}+\log (\mathrm{Cm})
$$

where the capacitance $\mathrm{Cm}$ must be expressed in pF.

Values of DHI for the intact teeth and for the respective drilling depths of $0.5 \mathrm{~mm}$ (group 1 composed by PM and

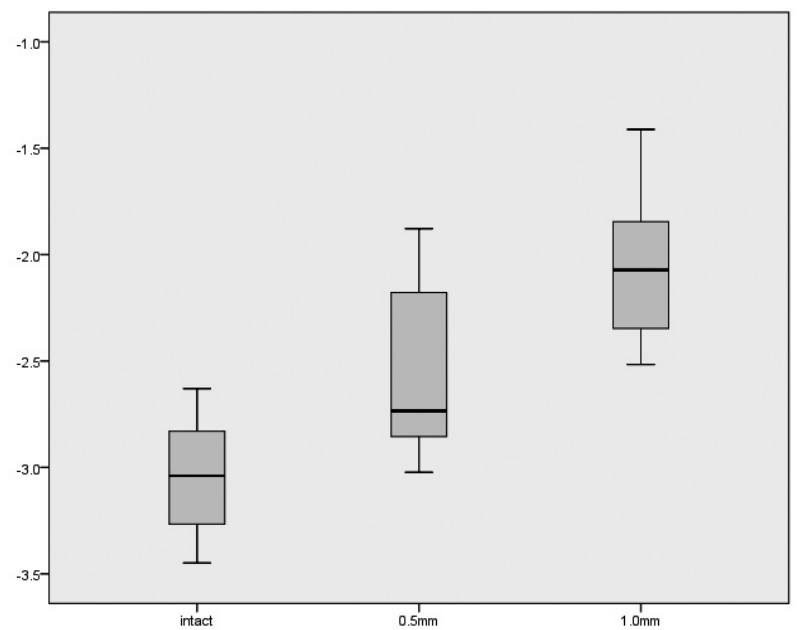

Figure 4. Values of the Huysmans' dental index (HI) derived from the bioimpedance parameters $R_{1}, R_{2}$, and $\mathrm{Cm}$ for premolars and third molars $(\mathrm{n}=15)$. See the text for more details.
TM teeth) and $1.0 \mathrm{~mm}$ (group 2 composed by PM and TM teeth) are depicted in Figure 5. This index differentiated the successive removal of the enamel layer independent of the tooth (TM or PM). Wilcoxon test applied to compare values of DHI between groups (intact, group 1 and group 2) pointed $p$ values smaller than 0.002 .

\section{Discussion}

The findings of the present study agree with previous works $(1,10,11)$ in the sense that $R_{1}$ seems to the most important parameter of a dental bioimpedance model, and also that the tooth bioimpedance parameters have a considerable variability (Tables 1, 2 and 3). Despite such a fact the BIS technique used in the present study was capable of differentiating the dental faces (smooth and fissured) for two types of intact studied teeth (TM and PM). The study also indicated that measures performed on different sites of these two types of surfaces have impedance parameters $\left(R_{1}, R_{2}\right.$ and $\left.\mathrm{Cm}\right)$ considered statistically similar.

Values of $R_{1}$ were higher for smooth surfaces when compared with the values observed in the fissured ones $(p<0.0001)$. Such a finding agrees with previous studies that also observed lower electrical resistance in fissured enamel. This seems to be correlated with the fact that the most important element of electrical impedance of the tooth is normally the enamel layer $(2,12)$. Thus, in fissure surfaces there is reduction of the thickness of the enamel and a consequent decrease in the impedance of the tooth in these surfaces.

When comparing values of $R_{1}$ and $\mathrm{Cm}$ regarding the dental type, one can observe that the mean value of $R_{1}$ for PM teeth is higher than the one associated to TM

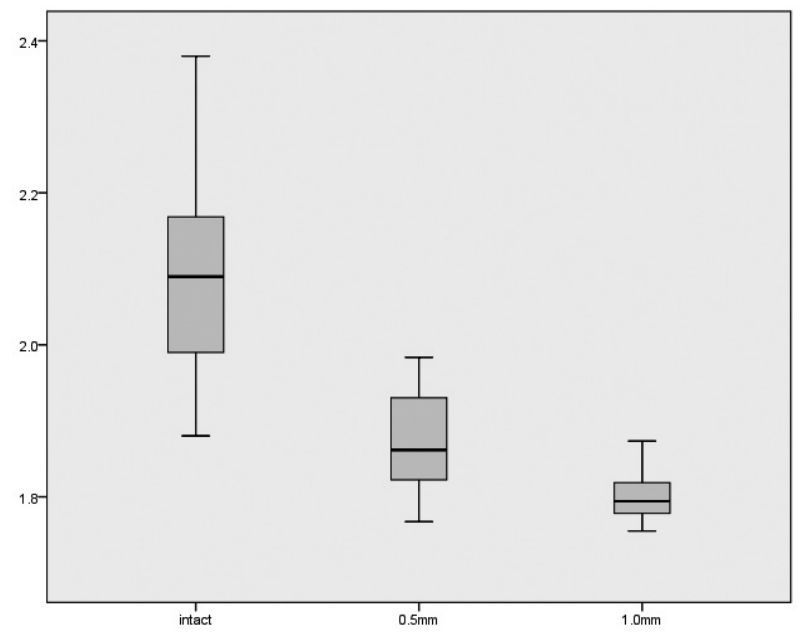

Figure 5. Values of the proposed dental health index (DHI) derived from the bioimpedance parameters $R_{1}, R_{2}$, and $\mathrm{Cm}$ for premolars and third molars $(n=15)$. 
teeth $(p<0.0001) .0 n$ the other hand, mean value of $\mathrm{Cm}$ presented an opposite behavior $(p<0.01)$. Such findings are probably associated with the fact that TM are normally bigger than PM, presenting a thicker enamel layer and greater inner volume.

Enamel thickness is expected to influence the electrical impedance of the tooth because the resistance of a body increases with the length of the conduction path. Thus, the greater the thickness that must be traversed by the current, the greater the electrical resistance (16). Accordingly, higher impedance values are expected for the smooth surfaces that present large thickness enamel/dentin compared with pits and fissures $(2,12)$.

Significant differences were observed for the bioimpedance parameters $R_{1}$ and $\mathrm{Cm}$ regarding the two studied type of teeth, and the different surfaces in the same tooth. On the other hand, parameter $R_{2}$ did not shown any difference between the fissured and smooth faces. These findings can be associated with the fact that the electric model (Fig. 1C) used for estimate the bioimpedance parameters can be considered a structural model (16), where $R_{1}$ would be associated to the resistance of the enamel layer; and $R_{2}$ and $\mathrm{Cm}$ would represent, respectively, the resistance and the capacitance associated to the dentin and pulp layers. Others studies $(11,12)$ have used similar models and have found that the $R_{1}$ parameter is far more correlated to the healthy tooth than $R_{2}$ or $C m$, despite using multifrequency sinusoidal sweep technique to estimate parameters of the associated electric model.

A dental index can be thought as a summary indicator that assesses morphological and physiological changes of the tooth. The proposed DHI was based on the observation of the behavior of the studied bioimpedance parameters in the several experiments performed. In this sense, we decided to include the parameter $\mathrm{Cm}$ (reactive part of the bioimpedance) in $\mathrm{DHI}$ because this parameter presented a substantial change associated to enamel loss. Thus, assuming the impedance of the tooth decreases as a carious lesion arises, it is supposed that the DHI might be used to assess dental health. Such a hypothesis is supported by the findings that $\mathrm{DHI}$ for the intact PM and TM shown in Figure 3 were sensitive enough to detect the mechanical removal of $0.5 \mathrm{~mm}$ and $1.0 \mathrm{~mm}$ layers of enamel with a higher statistical significance $(p<0.02)$, independent of the type of tooth.

To investigate the potentiality of DHI in the assessment of dental health, a small exploratory experiment with two unhealthy PM teeth was performed (impedance data not included). Surfaces of PM teeth present, respectively, active (white spots) and small carious lesions. Oral bacteria convert all foods, especially sugar and starch, into acids. Thus, dental caries often starts as an opaque white spot on the tooth surface. Such a spot generally indicates an area where bacterial acids are leaching minerals from the tooth enamel. If demineralization continues, the enamel and dentin are destroyed, forming a cavity. In the exploratory experiment DHI was 1.9 for the premolar with small carious lesions, which were closer to the median of group 2 associated with a $1.0 \mathrm{~mm}$ removal of enamel. The premolar with the active white spot exhibited DHI of about 1.8 , which is beyond the limits of the wide variance for drilling $0.5 \mathrm{~mm}$ of the smooth surface (Fig. 3).

In conclusion, a bipolar BIS technique based on the current response to a voltage step excitation was investigated in order to evaluate its feasibility to assess changes in the tooth structure. The results showed the behavior of bioimpedance parameters $\left(R_{1}, R_{2}\right.$, and $\left.\mathrm{Cm}\right)$ of intact teeth, as well as in successive removal of the enamel layer, allowing the proposition of a dental health index DHI. Results of a controlled in vitro experiment, as well as of a small exploratory experiment using two carious teeth, indicated that $\mathrm{DHI}$ was sensitive to detect the removal of the smooth enamel layer in PM and TM teeth and to distinguish different stages of cavity.

\section{Resumo}

Nos últimos anos a bioimpedância tem sido usada em aplicações odontológicas tais como estimativas de profundidade do canal radicular e na investigação de propriedades do esmalte. Apesar do número significativo de estudos usando a técnica de bioimpedância para avaliar a estrutura dental, muitos trabalhos usam somente a componente real da bioimpedância, isto é, a resistência; desprezando a informação fornecida pela parte imaginária, isto é, a reatância. Além disso, em diversos trabalhos que investigam ambas as partes da bioimpedância, os dados são, geralmente, obtidos por métodos monofrequenciais ou multifrequenciais baseados na varredura senoidal. 0 objetivo deste estudo foi investigar o uso de um método alternativo de espectroscopia de bioimpedância (BIS) baseado na resposta de corrente a um degrau de tensão na avaliação da estrutura do dente. Para testar a viabilidade do método alternativo realizamos experimentos in vitro que consideraram a remoção da camada de esmalte de 22 dentes hígidos, a aplicação do método BIS e a estimativa de parâmetros de bioimpedância que foram associados às mudanças na estrutura do dente. Para enfrentar o problema da variabilidade dos parâmetros de bioimpedância um índice de saúde dental (DHI) é proposto. Os resultados incluem o comportamento dos parâmetros de bioimpedância de dentes hígidos, assim como aqueles associados às sucessivas remoções da camada de esmalte; indicando que o DHI é sensivel para detectar mudanças na camada de esmalte. Os achados apontam para a viabilidade do método de BIS estudado na avaliação da estrutura do dente e que ele poderia ser usado para quantificação da saúde dental.

\section{Acknowledgements}

This work was supported by the Brazilian research funding agencies CNPq and CAPES.

\section{References}

1. Guimera $A$, Calderon $E_{1}$ Los $P$, Christie AM. Method and device for bioimpedance measurement with hard-tissue applications. Physiol Meas 2008;29:279-290.

2. Pita M, Jan H, Soujanya C, Donald JW, Vladimir G, Evgeny K. Permeability 
of human tooth surfaces studied in vitro by electrochemical impedance spectroscopy. electroanalysis 2012;24:1033-1038.

3. Kuhnisch J, Heinrich-Weltzien R, Tabatabaie M, Stosser L, Huysmans MC. An in vitro comparison between two methods of electrical resistance measurement for occlusal caries detection. Caries Res 2006:40:104-111.

4. Teo TK, Ashley PF, Louca C. An in vivo and in vitro investigation of the use of ICDAS, DIAGNOdent pen and CarieScan PRO for the detection and assessment of occlusal caries in primary molar teeth. Clin Oral Investig 2014;18:737-44.

5. Soares RMV, Silva EJNL, Herrera DR, Krebs RL, Coutinho-Filho TS. Evaluation of the Joypex 5 and Root ZX II: an in vivo and ex vivo study. Int Endod J 2013;46:904-909.

6. Twetman S, Axelsson S, Dahlén G, Espelid I, Mejàre I, Norlund A, et al.. Adjunct methods for caries detection: a systematic review of literature. Acta Odontol Scand 2013;71:388-397.

7. Gomez J, Tellez M, Pretty I, Ellwood A, Ismail RP. Non-cavitated carious lesions detection methods: a systematic review. Community Dent Oral Epidemiol 2013;41:55-66.

8. Ellwood RP, Cortes DF. In vitro assessment of methods of applying the electrical caries monitor for the detection of occlusal caries. Caries Res 2004;38:45-53.

9. Pitts NB, Longbottom C, Ricketts D. Hidden dentinal caries detection using a novel electrical impedance device. Caries Res 2008;42:185-238.

10. Los P, Pitts NB, Longbottom C. Application of percolation theory to human tooth enamel electrical conductivities at different stages of caries. Caries Res 2006;40:303-358.

11. Liao YM, Feng ZD, Chen ZL. In situ tracing the process of human enamel demineralization by electrochemical impedance spectroscopy (EIS). J Dent 2007;35:425-430.

12. Huysmans MC, Longbottom C, Pitts NB, Los P, Bruce PG. Impedance spectroscopy of teeth with and without approximal caries lesions - an in vitro study. J Dent Res 1996;75:1871-1878.

13. Kohn WG, Collins AS, Cleveland JL, Harte JA, Eklund KJ, Malvitz DM. Guidelines for infection control in dental health-care settings. MMWR Recomm Rep 2003;52:1-61.

14. Neves CE, Souza MN. A method for bio-electrical impedance analysis based on a step-voltage response. Physiol Meas 2000;21:395-408.

15. Huysmans MC, Longbottom C, Christie AM, Bruce PG, Shellis RP. Temperature dependence of the electrical resistance of sound and carious teeth. J Dent Res 2000;79:1464-1468.

16. Grimnes $S$, Martinsen $\emptyset$ G. Data and models. In: Bioelectricity and Bioimpedance Basics. 2nd ed. New York: Academic Press; 2008. p 283332. 